\title{
Numb and Alzheimer's disease: the current picture
}

\author{
Dimitrios Ntelios ${ }^{1}$, Benedikt Berninger ${ }^{2}$ and Georgios Tzimagiorgis ${ }^{1}$ * \\ ${ }^{1}$ Laboratory of Biological Chemistry, Medical School, Aristotle University of Thessaloniki, Thessaloniki, Greece \\ ${ }^{2}$ Department of Physiological Genomics, Institute of Physiology, Ludwig-Maximilians University Munich, Munich, Germany
}

Edited by:

Angelique Bordey, Yale University

School of Medicine, USA

\section{Reviewed by:}

Joshua Breunig, Cedars-Sinai Medical

Center, USA

Mladen-Roko Rasin, Robert Wood

Johnson Medical School, USA

${ }^{*}$ Correspondence:

Georgios Tzimagiorgis, Laboratory of Biological Chemistry, Medical School,

Aristotle University of Thessaloniki,

54124 Thessaloniki, Greece.

e-mail: tzimagio@med.auth.gr
Twenty-three years ago, numb was identified as a critical regulator in Drosophila sensory organ precursor cell asymmetric divisions. Beyond the recently recognized role in carcinogenesis, Numb seems to be important in Alzheimer's disease. This assertion comes from the involvement in various processes such as synapse morphogenesis, amyloid precursor protein trafficking, notch signaling, and neurogenesis. The purpose of the present minireview is to provide the current picture of Numb's participation in mechanisms underlying Alzheimer's disease pathogenesis and emphasize potential aspects for future research.

\section{Keywords: Alzheimer's disease, numb, neurogenesis, notch signaling}

\section{INTRODUCTION}

Alzheimer's disease (AD) is a serious debilitating neurodegenerative disorder described by the German psychiatrist and neuropathologist Alois Alzheimer in 1906 during a lecture in Tubingen. It is the most common form of dementia affecting millions of people worldwide. The major clinical manifestations are memory loss and cognitive decline. The primary neuropathological features of this disorder is neuronal cell death, synaptic loss, amyloid plaques, and neurofibrillary tangles with a unified theory explaining those findings a major unresolved issue. Amyloid plaques are extracellular deposits containing $\mathrm{A} \beta$ peptide, a proteolytic product derived from the amyloid precursor protein (APP). Mainly there are two modes of proteolysis: the sequential action of $\beta$ and $\gamma$ secretase which generates the $A \beta$ peptide (amyloidogenic mode) and the $\alpha$ and $\gamma$ secretase pathway (non-amyloidogenic mode). Neurofibrillary tangles are aggregates of hyperphosphorylated tau, a microtubule associated protein (Selkoe, 2001). A very important milestone in this century of $\mathrm{AD}$ research was the identification of presenilin 1 coding gene PSEN1 as a familiar AD cause (Sherrington et al., 1995). In this study Drosophila numb human homolog was mapped due to its location $50 \mathrm{~kb}$ away from PSEN1. Since then, there are many indications from the published literature that Numb may play a role in Alzheimer's disease pathogenesis and progression.

\section{NUMB OVERVIEW}

Initially numb was described as a cell fate determinant during sensory organ development in Drosophila embryos. Its name eloquently describes the sensory neuron depletion caused by numb loss of function mutations (Uemura et al., 1989). In humans there are two homologous genes, $N U M B$ and NUMB-Like. NUMB, located in 14q23, consists of 13 exons and by alternative splicing produces at least nine different transcripts (Haider et al., 2011). The mRNA binding protein Musashi-1 (Kawahara et al., 2008) and miR146a (Kuang et al., 2009) downregulate Numb protein levels. Numb does not have any enzymatic activity instead with its protein interaction domains acts as a molecular scaffold. Adhesion molecules, kinases, endocytic proteins, and ubiquitin ligases are the Numb's interacting network partners and reflect its multiple physiological roles (Gulino et al., 2010). Numb associates with membranes and the subcellular localization is regulated by Gcoupled receptors (Dho et al., 2006) and several kinases among them aPKC (Smith et al., 2007), Ca2+/calmodulin-dependent protein kinases (Tokumitsu et al., 2005), AAK1 (Sorensen and Conner, 2008). At last, conjugation of ubiquitin by LNX (Nie et al., 2002), Siah-1 (Susini et al., 2001), Mdm2 (Colaluca et al., 2008) targets Numb for proteasomal degradation.

\section{NUMB ENDOCYTOSIS AND APP TRAFFICKING}

Numb is a clathrin-associated sorting protein (CLASP) recognizing the [FY]XNPX[YF] motif (X any aminoacid; Traub, 2009). By its DPF and NPF motif (see Figure 1) binds to AP-2 subunit $\alpha$-adaptin (Santolini et al., 2000) and EPS15 (Salcini et al., 1997) accordingly, well known constituents of the endocytic machinery. It acts not only in the clathrin mediated endocytosis, but also in the Arf6 pathway and to the endocytic recycling through its interaction with EDH1 and EHD4 proteins (Smith et al., 2004). Different molecules like: L1 (Nishimura et al., 2003), integrin-b (Nishimura and Kaibuchi, 2007), E-cadherin (Kuo et al., 2006; Rasin et al., 2007; Sato et al., 2011) require numb for their endocytosis and proper membrane targeting.

In $\mathrm{AD}$ neurons endocytosis is impaired, with the detection of enlarged endosomes as an early neuropathological finding (Cataldo et al., 1997). Interestingly, approximately $70 \%$ of the $A \beta$ peptide secreted to the interstitial fluid is generated by endocytosis related mechanisms (Cirrito et al., 2008). Because $\alpha$ secretase predominantly localizes to the cellular membrane whereas $\beta$ secretase to acidic intracellular compartments (endosomes), APP's intracellular trafficking has a principal role in amyloidogenesis (Small and Gandy, 2006). There is evidence that Numb may serve as a modulator of APP sorting. Based on FRET and immunoprecipitation experiments, a direct interaction between Numb and APP 


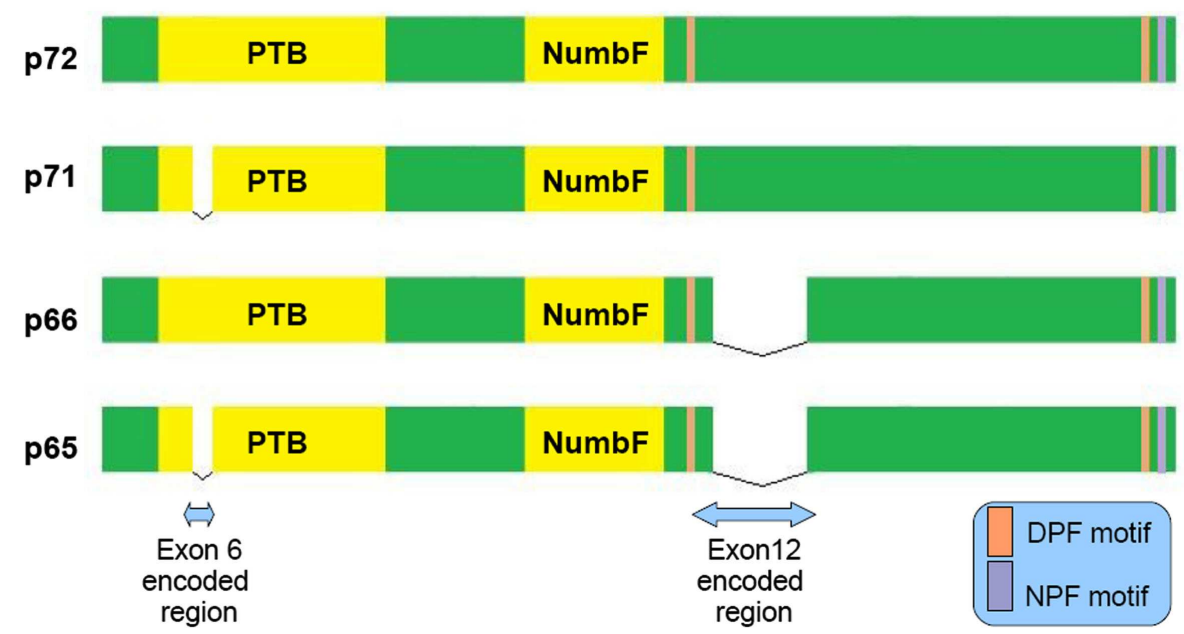

FIGURE 1 | Schematic representation of the four main Numb isoforms and their domain structure. PTB (Phosphotyrosine Binding Domain), NumbF (Numb family of proteins domain), NPF (asparagine-proline-phenylalanine), DPF (aspartate-proline-phenylalanine).

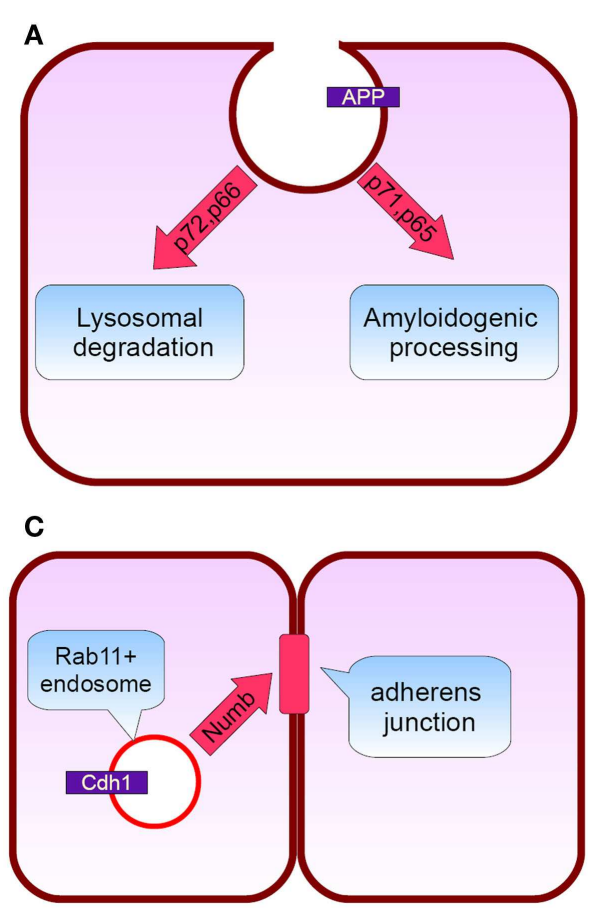

FIGURE 2 | Numb protein functions relevant to Alzheimer's disease. (A) APP subcellular trafficking: p72 and p66 isoforms (exon 6+) promote APP rooting to lysosomes whereas p71 and p65 (exon 6-) APP amyloidogenic processing (B) Notch, neurotrophins, and calcium signaling pathways fine

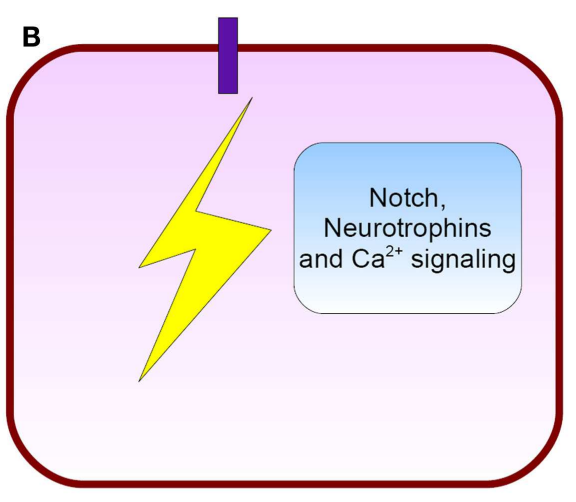

D

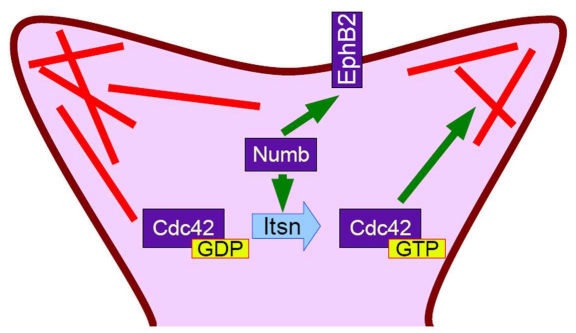

tuning, (C) Cadherin 1 targeting to adherens junctions and subsequently neurepithelium architecture preservation, (D) Numb interacts directly with EphB2 and additionally induces Intersectin's GTP for GDP exchange action on Cdc42. Cdc42 regulate spine dynamics by local actin remodeling (red lines). cytoplasmic tail through Numb phosphotyrosine binding domain (PTB) is established (Roncarati et al., 2002). Numb PTB domain recognizes the YENTPY conserved motif in APP cytoplasmic tail (Roncarati et al., 2002). The affinity of these interaction depends upon the Numb isoform examined and APP intracellular domain phosphorylation status (Tamayev et al., 2009). According to those in vitro data the increased Thr668 and Tyr682 phosphorylation in $\mathrm{AD}$ patients makes this interaction weaker (Lee et al., 2003). Also the p71 isoform (see Figure 1) docks with a greater affinity than the p72 (Tamayev et al., 2009). Many molecules comprising the APP intracellular part interactome are PTB domain containing proteins. Characteristic examples are Fe65, JIP, X11 $\alpha$, and $\beta$, whose 
role in $\mathrm{AD}$ has attracted researchers interest (King and Turner, 2004). Undoubtedly all those factors consist a fine tuned protein network and alterations could have negative or positive implications, e.g., $\mathrm{X} 11 \alpha$ slows APP processing reducing $\mathrm{A} \beta$ deposition (King et al., 2003).

$N U M B$ exon 6 alternative splicing give rise to isoforms that differentially affect APP processing. Exon 6 encodes a 11 aminoacid sequence in Numb PTB domain. Human exon 6- isoforms overexpression increase A $\beta$ production in SH-SY5Y cells bearing the Swedish double mutation K595N/M596L in APP. On the other hand exon $6+$ isoforms lead to lower $A \beta$ production than Numb wild type cells. This result is attributed to different subcellular APP trafficking. Exon $6+$ isoforms induce higher APP routing to lysosomes for degradation whereas exon 6- favor APP recycling (Kyriazis et al., 2008). Additionally Numb-like promote APP amyloidogenic processing (Schobel et al., 2006). In cortical cell cultures treated with $\mathrm{A} \beta$, exon 6 - isoforms are upregulated (Chigurupati et al., 2011). Interestingly, the same study reports increased Numb exon 6- protein isoforms in triple transgenic AD mouse model and parietal cortex from affected individuals. An important open question is the exact numb levels in the hippocampus from $\mathrm{AD}$ patients (an area great interest in $\mathrm{AD}$ ) due to the elevated Musashi-1 (rna binding protein downregulating numb mrna) reported elsewhere (Lovell and Markesbery, 2005). In contrast to $\mathrm{AD}$, reduced numb levels correlated with cancer development as shown in breast (Pece et al., 2004) and lung carcinomas (Westhoff et al., 2009). Whether Numb levels provide a biological explanation of why $\mathrm{AD}$ patients have lower incidence of malignancies than age-matched controls, remains to be clarified (Roe et al., 2010).

\section{NUMB AND NEUROGENESIS}

In adult life nerve cells are continually born in the subgranular zone of the dentate gyrus and the subventricular zone (Curtis et al., 2011). Studies in humans and familiar Alzheimer's disease mouse models, despite some controversies, demonstrated alterations in neurogenesis (Lazarov and Marr, 2010). Numb is essential for the asymmetric divisions during Drosophila embryo peripheral and central nervous system development. Due to its ability to interact with dividing cell's polarity mechanisms, has the potential to distribute asymmetrically between the two daughter cells thereby enabling them to choose a different cell fate, acting as a binary switch (Zhong, 2008). On the contrary, there is an open discussion about the exact role in cell fate determination during asymmetric cell divisions in mammals. However, it is evident that numb plays critical role during mammalian neurogenesis also. Several Numb/Numbl conditional double knockout mice demonstrated severe defects in brain development (Petersen et al., 2002, 2004; Li et al., 2003). It is proposed that Numb is crucial for the neurepithelium architecture maintenance. It associates with Rab11+ recycling endosomes containing Cadherin 1 and is essential for the correct membrane targeting of this adherens junction component (Rasin et al., 2007). Postnatal Numb/numbl deletion seriously compromises ependymal wall integrity and subventricular zone homeostasis (Kuo et al., 2006). Despite the recent data indicating that SVZ neurogenesis largely stops after 18 months of age (Sanai et al., 2011) there are reports that stroke (Marti-Fabregas et al., 2010) and Huntington disease induce a substantial upregulation (Curtis et al., 2003). Furthermore, numb modulates signaling pathways such as Hedgehog (Marcotullio et al., 2006) and Notch with well recognized role in adult neurogenesis (Lai et al., 2003; Imayoshi et al., 2010).

\section{NUMB AND SYNAPSE MORPHOGENESIS}

A very interesting observation in $\mathrm{AD}$ is the dramatic reduction in dendritic spines and its good correlation with disease progression (Terry et al., 1991). Cortical rewiring through new synapse formation is a key mechanism for memory and cognition (McAllister, 2007). Numb affects synapse formation through several mechanisms. In particular, Numb p72 isoform overexpression in cultured hippocampal neurons leads to an increase in spine length. In the case of aminoacid 1-183 and 184-592 fragment overexpression, an additional decrease in spine density and percentage of protrusions with a spine head is observed. Numb interacts with intersectin [possesses a guanine nucleotide exchange factor (GEF) activity for Cdc42], Rac GEF Tiam1, and dual Rho GEF Kalirin. Cdc42, Rac, and Rho are members of the Rho family GTPases (Nishimura et al., 2006). They regulate actin dynamics and have a pivotal role in synapse formation as reflected from the mental retardation syndromes linked to genes participating in this signaling pathway (Ramakers, 2002). GEFs activate Rho proteins by a GTP for GDP exchange. In the case of intersectin we have to mention that is a chromosome 21 encoded protein with a direct involvement in Down syndrome (Chang and Min, 2009). At last, Numb interact with NMDA glutamate receptors and EphB2 (Nishimura et al., 2006). EphB2 is essential for the synapse to function properly (Lai and Ip, 2009) and is downregulated in AD brains (Cisse et al., 2011).

\section{NUMB AND SIGNALING PATHWAYS}

Much work has focused on the regulation of intracellular signaling cascades by Numb. First of all, Numb is the classical Notch pathway inhibitor. Mammals have four different Notch receptors mediating cell-cell communication (Brou, 2009). In adult nervous system, Notch signaling has linked with various functions from long term potentiation (Wang et al., 2004), to dendrite arborization (Berezovska et al., 1999) and neurogenesis (Breunig et al., 2007; Imayoshi et al., 2010). The p66 isoform was shown to promote Notch 1 ubiquitination by recruiting E3 ubiquitin ligase Itch (McGill and McGlade, 2003; McGill et al., 2009). The ability to exert a repressive effect on Notch signaling differs between Numb isoforms (Beres et al., 2011). It is proposed that AICD (APP's C terminal part generated from $\gamma$ cleavage) binds Numb and inhibits Notch (Roncarati et al., 2002). In the case of Notch 1 and 2 receptors, a direct interaction with APP was observed (Chen et al., 2006). Interestingly, Notch 1 immunoreactivity in the hippocampus of AD patients was increased (Berezovska et al., 1998). Similarly to APP, Notch receptors are $\alpha$ and $\gamma$ secretase substrates with this proteolytic events being prerequisite for signal transduction. This is why, in the field of $\mathrm{AD}$ therapeutics, the main obstacle toward a safe $\gamma$ secretase inhibitor is the compromised Notch signaling related toxicities (Oehlrich et al., 2011).

Beyond Notch, Numb seems to play a role in neurotrophin signaling. This pathway promotes neuronal survival (Heumann, 
1994) and is perturbed in AD brains (Williams et al., 2006). Especially the TrkA and TrkB receptors are downregulated (Ginsberg et al., 2006). Recently a study demonstrated that Numb required for TrkB endocytosis and migration of cerebellum granule cells across BDNF gradient (Zhou et al., 2011). PC12 cell overexpressing exon 6- isoforms display increased NGF induced neurite outgrowth partly due to increased TrkA levels (Pedersen et al., 2002). This outgrowth is a well recognized phenomenon which makes PC12 cells a popular neuronal model. Furthermore TrkA and TrkB endocytosis in sympathetic and hippocampal neurons requires EHD4 (Pincher), a Numb binding partner (Valdez et al., 2005).

Several lines of evidence point toward a contribution to the calcium mishandling observed in $\mathrm{AD}$ (Supnet and Bezprozvanny, 2010). Exon 6- isoforms overexpression in PC12 cells induce neurite outgrowth without requiring NGF treatment in a way depending upon voltage-gated calcium channels (Lu et al., 2009). Additionally these cells are more vulnerable to $\mathrm{A} \beta$ toxicity due to a calcium related mechanism (Chan et al., 2002) and after trophic factor withdrawal from the culture medium TRPV6 is upregulated leading to calcium dysregulation and increased cell death (Kyriazis et al., 2010).

Recently, an interesting finding was that Numb interacts with the cell cycle regulatory protein Polo-like kinase 1 (Plk1; Schmit et al., 2012). Plk1 activity is elevated in AD patients and PLK1 silencing reduces $A \beta$-induced neuronal cell death (Song et al., 2011). Indeed, a link between cell cycle disturbances and neuronal death has now been established in $\mathrm{AD}$. It is proposed

\section{REFERENCES}

Beres, B. J., George, R., Lougher, E. J., Barton, M., Verrelli, B. C., McGlade, C. J., et al. (2011). Numb regulates Notch1, but not Notch3, during myogenesis. Mech. Dev. 128, 247-257.

Berezovska, O., McLean, P., Knowles, R., Frosh, M., Lu, F. M., Lux, S. E., et al. (1999). Notch1 inhibits neurite outgrowth in postmitotic primary neurons. Neuroscience 93, 433-439.

Berezovska, O., Xia, M. Q., and Hyman, B. T. (1998). Notch is expressed in adult brain, is coexpressed with presenilin-1, and is altered in Alzheimer disease. J. Neuropathol. Exp. Neurol. 57, 738-745.

Breunig, J. J., Silbereis, J., Vaccarino, F. M., Sestan, N., and Rakic, R. (2007). Notch regulates cell fate and dendrite morphology of newborn neurons in the postnatal dentate gyrus. Proc. Natl. Acad. Sci. U.S.A. 104, 20558-20563.

Brou, C. (2009). Intracellular trafficking of Notch receptors and ligands. Exp. Cell Res. 315, 1549-1555.

Cataldo, A. M., Barnett, J. L., Pieroni, C., and Nixon, R. (1997). Increased neuronal endocytosis and protease delivery to early endosomes in sporadic Alzheimer's disease: neuropathollogic evidence for a mechanism of increased $\beta$ amyloidogenesis. J. Neurosci. 17, 6142-6151.

Chan, S. L., Pedersen, W. A., Zhu, H., and Mattson, M. P. (2002). Numb modifies neuronal vulnerability to amyloid beta-peptide in an isoformspecific manner by a mechanism involving altered calcium homeostasis: implications for neuronal death in Alzheimer's disease. Neuromolec-

Chang, K. T., and Min, K. T. (2009). Upregulation of three Drosophila homologs of human chromosome 21 genes alters synaptic function: implications for Down syndrome. Proc. Natl. Acad. Sci. U.S.A. 106, 17117-17122.

Chen, C. D., Oh, S. Y., Hinman, J. D., and Abraham, C. R. (2006). Visualization of APP dimerization and APPNotch2 heterodimerization in living cells using bimolecular fluorescence complementation. J. Neurochem. 97, 30-43.

Chigurupati, S., Madan, M., Okun, E., Wei, Z., Pattisapu, J. V., Mughal, M. R., et al. (2011). Evidence for altered Numb isoform levels in Alzheimer's disease patients and a triple transgenic mouse model. J. Alzheimers Dis. 24, 349-361. ular Med. 1, 55-67.

that inappropriate reentry into a mitotic cell cycle triggers neuronal cell death (Herrup, 2012). In this context, cyclin-dependent kinase 5, which prevent this reentry (Zhang et al., 2010) regulates collapsin response mediator protein-2 (CRMP-2). Of note, CRMP-2 has a role in Numb-mediated endocytosis (Nishimura et al., 2003), is phosphorylated early in AD (Cole et al., 2007) and is a substrate for glycogen synthase kinase 3 (Gsk3ß; Cole et al., 2004), a known molecular player in $\mathrm{AD}$ (Kremer et al., 2011).

\section{CONCLUSION}

There is already ample in vitro evidence that this protein affect neurodegeneration in multiple ways. In vivo, Numb exon 6- isoforms has been shown to increase in both triple transgenic AD mouse model and affected human individuals. In the future the development of mice bearing a known $\mathrm{AD}$ causing mutation with targeted disruption of specific Numb isoforms will provide a unique angle to approach the study of Numb's role in $\mathrm{AD}$. To what extent $\mathrm{AD}$ pathogenic pathways are Numb-dependent in vivo is not yet clear but considering the data provided so far there are many exciting findings to come in the next years. The clinical significance of this molecule as a potential drug target or biomarker remains to be convincingly demonstrated by future studies. The fact that Numb has a tumor suppressor activity, makes problematic target for future drug research. However elucidating further the physiological relevance of this Numb APP interaction could provide us with a more complete understanding of the mechanisms involved in this devastating illness.

Cirrito, J. R., Kang, J. E., Lee, J., Stewart, F. R., Verges, D. K., Silverio, L. M., et al. (2008). Endocytosis is required for synaptic activity dependent release of amyloid- $\beta$ in vivo. Neuron 58, 42-51.

Cisse, M., Halabisky, B., Harris, J. Devidze, N., Dubal, D. B., Sun, B., et al. (2011). Reversing EphB2 depletion rescues cognitive functions in Alzheimer model. Nature 469, 47-52.

Colaluca, I. N., Tosoni, D., Nuciforo, P., Senic-Matuglia, F., Galimberti, V., Viale, G., et al. (2008). NUMB controls p53 tumor suppressor activity. Nature 451, 76-80.

Cole, A. R., Knebel, A., Morrice, N. A., Robertson, L. A., Irving, A. J., Connolly, C. N., et al. (2004). GSK-3 phosphorylation of the Alzheimer epitope within collapsin response mediator proteins regulates axon elongation in primary neurons. $J$. Biol. Chem. 279, 50176-50180.

Cole, A. R., Noble, W., van Aalten, L., Plattner, F., Meimaridou, R., Hogan, D., et al. (2007). Collapsin response mediator protein-2 hyperphosphorylation is an early event in Alzheimer's disease progression. J. Neurochem. 103, 1132-1144.

Curtis, M. A., Kam, M., and Faull, R. L. (2011). Neurogenesis in humans. Eur. J. Neurosci. 33, 1170-1174.

Curtis, M. A., Penney, E. B., Pearson, A. G., van Roon-Mom, W. M. C., Butterworth, N. J., Dragunow, M., et al. (2003). Increased cell proliferation and neurogenesis in the adult human Huntington's disease brain. Proc. Natl. Acad. Sci. U.S.A. 100, 9023-9027.

Dho, S. E., Trejo, J., Siderovski, D. P., and McGlade, C. J. (2006). Dynamic regulation of mammalian numb by $\mathrm{G}$ protein-coupled receptors and protein kinase $\mathrm{C}$ activation: structural determinants of numb association with the cortical membrane. Mol. Biol. Cell 17, 4142-4155.

Ginsberg, S. D., Che, S., Wuu, J., Counts, S. E., and Mufson, E. J. (2006). Down regulation of trk but not $\mathrm{p} 75$ gene expression in single cholinergic basal forebrain neurons mark the progression of Alzheimer's disease. J. Neurochem. 97, 475-487.

Gulino, A., di Marcotullio, L., and Screpanti, I. (2010). The multiple functions of Numb. Exp. Cell Res. 316, 900-906.

Haider, M., Qiu, Q., Bani-Yaghoub, M., Tsang, B. K., and Gruslin, A. (2011) Characterization and role of NUMB in the human extravillous trophopblast. Placenta 32, 441-449. 
Herrup, K. (2012). The contributions of unscheduled neuronal cell cycle events to the death of neurons in Alzheimer's disease. Front. Biosci. 4, 2101-2109.

Heumann, R. (1994). Neurotrophin signalling. Curr. Opin. Neurobiol. 4, 668-679.

Imayoshi, I., Sakamoto, M., Yamaguchi, M., Mori, K., and Kageyama, R. (2010). Essential roles of Notch signaling in maintenance of neural stem cells in developing and adult brains. J. Neurosci. 30, 3489-3498.

Kawahara, H., Imai, T., Imataka, H., Tsujimoto, M., Matsumoto, K., and Okano, H. (2008). Neural RNAbinding protein Musashil inhibits translation initiation by competing with eIF4G for PABP. J. Cell Biol. 18, 639-653.

King, G. D., Perez, R. G., Steinhilb, M. L., Gaut, J. R., and Turner, R. S. (2003). X11alpha modulates secretory and endocytic trafficking and metabolism of amyloid precursor protein: mutational analysis of the YENPTY sequence. Neuroscience 120, 143-154.

King, G. D., and Turner, R. S. (2004). Adaptor protein interactions: modulators of amyloid precursor protein metabolism and Alzheimer's disease risk? Exp. Neurol. 185, 208-219.

Kremer, A., Louis, J. V., Jaworski, T., and VanLeuven, F. (2011). GSK3 and Alzheimer's disease: facts and fiction. Front. Mol. Neurosci. 4:17. doi:10.3389/fnmol.2011.00017

Kuang, W., Tan, J., Duan, Y., Duan, J., Wang, W., Jin, F., et al. (2009). Cyclic stretch induced miR-146a upregulation delays $\mathrm{C} 2 \mathrm{C} 12$ myogenic differentiation through inhibition of Numb. Biochem. Biophys. Res. Commun. 378, 259-263.

Kuo, C. T., Mirzadeh, Z., SorianoNavarro, M., Rasin, M., Wang, D., Shen, J., et al. (2006). Postnatal deletion of Numb/Numblike reveals repair and remodeling capacity in the subventricular neurogenic niche. Cell 127, 1253-1264.

Kyriazis, G. A., Belal, C., Madan, M., Taylor, D. G., Wang, J., Wei, Z., et al. (2010). Stress-induced switch in Numb isoforms enhances Notchdependent expression of subtypespecific transient receptor potential channel. J. Biol. Chem. 285, 6811-6825.

Kyriazis, G. A., Wei, Z., Vandermey, M., Jo, D. G., Xin, O., Mattson, M. P., et al. (2008). Numb endocytic adapter proteins regulate the transport and processing of the amyloid precursor protein in an isoform-dependent manner: implications for Alzheimer disease pathogenesis. J. Biol. Chem. 283, 25492-25502.

Lai, K., Kaspar, B. K., Gage, F. H., and Schaffer, D. V. (2003). Sonic hedgehog regulates adult neural progenitor proliferation in vitro and in vivo. Nat. Neurosci. 6, 21-27.

Lai, K. O., and Ip, N. Y. (2009). Synapse development and plasticity: roles of ephrin/Eph receptor signaling. Curr. Opin. Neurobiol. 19, 275-283.

Lazarov, O., and Marr, R. A. (2010). Neurogenesis and Alzheimer's disease: at the crossroads. Exp. Neurol. 223, 267-281.

Lee, M. S., Kao, S. C., Lemere, C. A., Xia, W., Tseng, H. C., Zhou, Y., et al. (2003). APP processing is regulated by cytoplasmic phosphorylation. $J$. Cell Biol. 163, 83-95.

Li, H. S., Wang, D., Shen, Q., Schonemann, M. D., Gorski, J. A., Jones, K. R., et al. (2003). Inactivation of numb and numblike in embryonic dorsal forebrain impairs neurogenesis and disrupts cortical morphogenesis. Neuron 40, 1105-1118.

Lovell, M. A., and Markesbery, W. R. (2005). Ectopic expression of Musashi-1 in Alzheimer disease and Pick disease. J. Neuropathol. Exp. Neurol. 64, 675-680.

Lu, C. B., Fu, W., Xu, X., and Mattson, M. P. (2009). Numb-mediated neurite outgrowth is isoform-dependent, and requires activation of voltagedependent calcium channels. Neuroscience 161, 403-412.

Marcotullio, L. D., Ferretti, E., Greco, A., De Smaele, E., Po, A., Sico, M. A., et al. (2006). Numb is a suppressor of Hedgehog signalling and targets Gli1 for Itch dependent ubiquitination. Nat. Cell Biol. 8, 1415-1423.

Marti-Fabregas, J., Romaguera-Ros, M., Gomez-Pinedo, U., MartinezRamirez, S., Jimenez-Xarrie, E., Marin, R., et al. (2010). Proliferation in the human ipsilateral subventricular zone after ischemic stroke. Neurology 74, 357-365.

McAllister, A. K. (2007). Dynamic aspects of CNS synapse formation. Annu. Rev. Neurosci. 30, 425-450.

McGill, M. A., Dho, S. E., Weinmaster, G., and McGlade, C. J. (2009). Numb regulates post-endocytic trafficking and degradation of Notch1. J. Biol. Chem. 284, 26427-26438.

McGill, M. A., and McGlade, C. J. (2003). Mammalian Numb proteins promote Notch1 receptor ubiquitination and degradation of the Notch1 intracellular domain. J. Biol. Chem. 278, 23196-23203.

Nie, J., McGill, M. A., Dermer, M., Dho, S. E., Wolting, C. D., and
McGlade, C. J. (2002). LNX functions as a RING type E3 ubiquitin ligase that targets the cell fate determinant Numb for ubiquitindependent degradation. EMBO J. 21 , 93-102.

Nishimura, T., Fukata, Y., Kato, K., Yamaguchi, T., Matsuura, Y., Kamiguchi, H., et al. (2003). CRMP-2 regulates polarized Numb-mediated endocytosis for axon growth. Nat. Cell Biol. 5, 819-826.

Nishimura, T., and Kaibuchi, K. (2007). Numb controls integrin endocytosis for directional cell migration with aPKC and PAR-3. Dev. Cell 13, 15-28.

Nishimura, T., Yamaguchi, T., Tokunaga, A., Hara, A., Hamaguchi, T., Kato, K., et al. (2006). Role of numb in dendritic spine development with a Cdc42 GEF intersectin and EphB2. Mol. Biol. Cell 17, 1273-1285.

Oehlrich, D., Berthelot, D. J., and Gijsen, H. J. (2011). $\gamma$-Secretase modulators as potential disease modifying antiAlzheimer's drugs. J. Med. Chem. 54, 669-698.

Pece, S., Serresi, M., Santolini, E., Capra, M., Hulleman, E., Galimberti, V., et al. (2004). Loss of negative regulation by Numb over Notch is relevant to human breast carcinogenesis. $J$. Cell Biol. 167, 215-221.

Pedersen, W. A., Chan, S. L., Zhu, H., Abdur-Rahman, L. A., Verdi, J. M., and Mattson, M. P. (2002). Numb isoforms containing a short PTB domain promote neurotrophic factor-induced differentiation and neurotrophic factor withdrawalinduced death of PC12 cells. J. Neurochem. 82, 976-986.

Petersen, P. H., Zou, K., Hwang, J. K., Jan, Y. N., and Zhong, W. (2002). Progenitor cell maintenance requires numb and numblike during mouse neurogenesis. Nature 419 , 929-934.

Petersen, P. H., Zou, K., Krauss, S., and Zhong, W. (2004). Continuing role for mouse Numb and Numbl in maintaining progenitor cells during cortical neurogenesis. Nat. Neurosci. 7, 803-811.

Ramakers, G. J. (2002). Rho proteins, mental retardation and the cellular basis of cognition. Trends Neurosci. 25, 191-199.

Rasin, M. R., Gazula, V. R., Breunig, J. J., Kwan, K. Y., Johnson, M. B., Liu-Chen, S., et al. (2007). Numb and Numbl are required for maintenance of cadherin-based adhesion and polarity of neural progenitors. Nat. Neurosci. 10, 819-827.

Roe, C. M., Fitzpatrick, A. L., Xiong, C., Sieh, W., Kuller, L., Miller, J. P., et al.
(2010). Cancer linked to Alzheimer disease but not vascular dementia. Neurology 74, 106-112.

Roncarati, R., Sestan, N., Scheinfeld, M. H., Berechid, B. E., Lopez, P. A., Meucci, O., et al. (2002). The g-secretase-generated intracellular domain of b-amyloid precursor protein binds Numb and inhibits Notch signaling. Proc. Natl. Acad. Sci. U.S.A. 99, 7102-7107.

Salcini, A. E., Confalonieri, S., Doria, M., Santolini, E., Tassi, E., Minenkova, O., et al. (1997). Binding specificity and in vivo targets of the EH domain, a novel protein-protein interaction module. Genes Dev. 11, 2239-2249.

Sanai, N., Nguyen, T., Ihrie, R. A., Mirzadeh, Z., Tsai, H. H., Wong, M., et al. (2011). Corridors of migrating neurons in the human brain and their decline during infancy. Nature 478, 382-386.

Santolini, E., Puri, C., Salcini, A. E., Gagliani, M. C., Pelicci, P. G., Tacchetti, C., et al. (2000). Numb is an endocytic protein. J. Cell Biol. 151, 1345-1352.

Sato, K., Watanabe, T., Wang, S., Kakeno, M., Matsuzawa, K., Matsui, T., et al. (2011). Numb controls E-cadherin endocytosis through p120 catenin with aPKC. Mol. Biol. Cell 22, 3103-3119.

Schmit, T. L., Nihal, M., Ndiaye, M., Setaluri, V., Spiegelman, V. S., and Ahmad, N. (2012). Numb regulates stability and localization of the mitotic kinase PLK1 and is required for transit through mitosis. Cancer Res. 72, 3864-3872.

Schobel, S., Neumann, S., Seed, B., and Lichtenthaler, S. F. (2006). Expression cloning screen for modifiers of amyloid precursor protein shedding. Int. J. Dev. Neurosci. 24, 141-148.

Selkoe, D. J. (2001). Alzheimer's disease: genes, proteins, and therapy. Physiol. Rev. 81, 741-766.

Sherrington, R., Rogaev, E. I., Liang, Y., Rogaeva, E. A., Levesque, G., Ikeda, M., et al. (1995). Cloning of a gene bearing missense mutations in earlyonset familial Alzheimer's disease. Nature 375, 754-760.

Small, S. A., and Gandy, S. (2006). Sorting throught the cell biology of Alzheimer's disease: intracellular pathways to pathogenesis. Neuron 52, 15-31.

Smith, C. A., Dho, S. E., Donaldson, J., Tepass, U., and McGlade, C. J. (2004). The cell fate determinant Numb interacts with EHD/Rme-1 family proteins and has a role in endocytic recycling. Mol. Biol. Cell 15, 3698-3708. 
Smith, C. A., Lau, K. M., Rahmani, Z., Dho, S. E., Brothers, G., She, Y. M., et al. (2007). aPKC-mediated phosphorylation regulates asymmetric membrane localization of the cell fate determinant Numb. EMBO J.26, 468-480.

Song, B., Davis, K., Liu, S. X., Lee, H., Smith, M., and Liu, X. (2011). Inhibition of Polo-like kinase 1 reduces beta-amyloid-induced neuronal cell death in Alzheimer's disease. Aging 3, 846-851.

Sorensen, E. B., and Conner, S. D. (2008). AAK1 regulates numb function at an early step in clathrinmediated Endocytosis. Traffic 9, 1791-1800.

Supnet, C., and Bezprozvanny, I. (2010). The dysregulation of intracellular calcium in Alzheimer disease. Cell Calcium 47, 183-189.

Susini, L., Passer, B. J., Amzallag-Elbaz, N., Juven-Gershon, T., Prieur, S., Privat, N., et al. (2001). Siah-1 binds and regulates the function of Numb. Proc. Natl. Acad. Sci. U.S.A. 98, 15067-15072.

Tamayev, R., Zhou, D., and d'Adamio, L. (2009). The interactome of the amyloid beta precursor protein family members is shaped by phosphorylation of their intracellular domains. Mol. Neurodegener. $4,28$.

Terry, R. D., Masliah, E., Salmon, D. R., Butters, N., De Teresa, R., Hill, R., et al. (1991). Physical basis of cognitive alterations in Alzheimer's disease: synapse loss is the major correlate of cognitive impairment. Ann. Neurol. 30, 572-580.

Tokumitsu, H., Hatano, N., Inuzuka, H., Sueyoshi, Y., Yokokura, S., Ichimura, T., et al. (2005). Phosphorylation of Numb family proteins. Possible involvement of $\mathrm{Ca} 2+/$ calmodulindependent protein kinases. J. Biol. Chem. 280, 35108-35118.

Traub, L. M. (2009). Tickets to ride: selecting cargo for clathrinregulated internalization. Nat. Rev. Mol. Cell Biol. 10, 583-596.

Uemura, T., Shepherd, S., Ackerman, L., Jan, L. Y., and Jan, Y. N. (1989). Numb, a gene required in determination of cell fate during sensory organ formation in Drosophila embryos. Cell 58, 346-360.

Valdez, G., Akmentin, W., Philippidou, P., Kuruvilla, R., Ginty, D. D., and Halegoua, S. (2005). Pincher-mediated macroendocytosis underlies retrograde signaling by neurotrophin receptors. J. Neurosci. 25, 5236-5247.

Wang, Y., Chan, S. L., Miele, L., Yao, P. J., Mackes, J., Ingram, D. K., et al. (2004). Involvment of Notch signaling in hippocampal synaptic plastisity. Proc. Natl. Acad. Sci. U.S.A 101, 9458-9462.

Westhoff, B., Colaluca, I. N., D’Ario, G., Donzelli, M., Tosoni, D., Volorio, S., et al. (2009). Alterations of the Notch pathway in lung cancer. Proc. Natl. Acad. Sci. U.S.A. 106, 22293-22298.

Williams, B. J., Eriksdotter-Jonhagen, M., and Granholm, A. C. (2006). Nerve growth factor in treatment and pathogenesis of Alzheimer's disease. Prog. Neurobiol. 80, 114-128.

Zhang, J., Li, H., Yabut, O., Fitzpatrick, H., D'Arcangelo, G., and Herrup, K. (2010). Cdk5 supresses the neuronal cell cycle by disrupting the E2F1-DP1 complex. J. Neurosci. 30, 5219-5228.

Zhong, W. (2008). Timing cell-fate determination during asymmetric cell divisions. Curr. Opin. Neurobiol. 18, 472-478.

Zhou, P., Alfaro, J., Chang, E. H., Zhao, X., Porcionatto, M., and Segal, R. A. (2011). Numb links extracellular cues to intracellular polarity machinery to promote chemotaxis. Dev. Cell 20, 610-622.

Conflict of Interest Statement: The authors declare that the research was conducted in the absence of any commercial or financial relationships that could be construed as a potential conflict of interest.

Received: 05 July 2012; paper pending published: 30 July 2012; accepted: 14 September 2012; published online: 04 October 2012.

Citation: Ntelios D, Berninger B and Tzimagiorgis G (2012) Numb and Alzheimer's disease: the curren picture. Front. Neurosci. 6:145. doi: 10.3389/fnins.2012.00145

This article was submitted to Frontiers in Neurogenesis, a specialty of Frontiers in Neuroscience.

Copyright (c) 2012 Ntelios, Berninger and Tzimagiorgis. This is an openaccess article distributed under the terms of the Creative Commons Attribution License, which permits use, distribution and reproduction in other forums, provided the original authors and source are credited and subject to any copyright notices concerning any third-party graphics etc. 